\title{
Effects of air pollutants on innate immunity: The role of Toll-like receptors and nucleotide-binding oligomerization domain-like receptors
}

\author{
Rebecca N. Bauer, BA ${ }^{\mathrm{a}}$, David Diaz-Sanchez, PhD ${ }^{\mathrm{d}}$, and llona Jaspers, PhD ${ }^{\mathrm{a}, \mathrm{b}, \mathrm{c}}$ \\ ${ }^{a}$ Curriculum in Toxicology, University of North Carolina at Chapel Hill \\ ${ }^{\mathrm{b}}$ Center for Environmental Medicine, Asthma, and Lung Biology, University of North Carolina at \\ Chapel Hill \\ 'Department of Pediatrics, University of North Carolina at Chapel Hill \\ dUS Environmental Protection Agency, National Health and Environmental Effects Research \\ Laboratory, Research Triangle Park
}

\begin{abstract}
Interactions between exposure to ambient air pollutants and respiratory pathogens have been shown to modify respiratory immune responses. Emerging data suggest key roles for Toll-like receptor (TLR) and nucleotide-binding oligomerization domain-like receptor (NLR) signaling in pathogen-induced immune responses. Similarly, immune responses elicited by exposure to air pollutants are mediated by specific TLR- and NLR-dependent mechanisms. This review article will summarize current knowledge about how air pollutants modify TLR- and NLR-dependent signaling and host defense responses in the lung.
\end{abstract}

\section{Keywords}

Toll-like receptor; NOD-like receptor; pattern recognition receptor; inflammasome; cigarette smoke; particulate matter; ozone; diesel exhaust; nanoparticles; air pollutant; innate immunity; host defense; pathogen-associated molecular pattern; danger-associated molecular pattern; lung; airway

\begin{abstract}
Since the 1970 Clean Air Act, many cities have experienced dramatic improvements in air quality. Levels of large particulate matter $\left(\mathrm{PM}_{10}\right)$ have decreased by $83 \%$ in this period, even though there has been an increase of $178 \%$ in the number of vehicle miles traveled. ${ }^{1}$ Despite these advances, the American Lung Association estimates that more than half of persons in the United States live in counties that have unhealthy levels of pollution. ${ }^{2}$ The last 40 years has also seen important advancements in our understanding of the risks posed
\end{abstract}

(C) 2012 American Academy of Allergy, Asthma \& Immunology

Corresponding author: Ilona Jaspers, PhD, 104 Mason Farm Rd, Chapel Hill, NC 27599-7310. ilona_japsers@med.unc.edu.

The article has been reviewed by the National Health and Environmental Effects Research Laboratory, US Environmental Protection Agency and approved for publication. Approval does not signify that the contents necessarily reflect the views and the policies of the Agency, nor does mention of trade names or commercial products constitute endorsement or recommendation for use. 
by high levels of both indoor and outdoor air pollutants on respiratory health. Accordingly, numerous reviews have described the potential of gaseous pollutants, such as ozone, and particulate pollutants, such as diesel, cigarette smoke (CS), and biomass, to impair lung function and exacerbate and promote asthma. ${ }^{3,4}$ In addition to direct physiologic changes, many have highlighted the ability of these agents to modulate the adaptive immune response and thereby increase IgE levels and promote a $\mathrm{T}_{\mathrm{H}} 2$ milieu that can promote allergic airway disease. ${ }^{5}$ Recently, there has been a growing appreciation that pollutants might also significantly affect respiratory innate immune responses.

Therefore here we will review the potential cellular mechanisms by which exposure to air pollutants modulates respiratory immunity and host defense. The public health significance is clear: respiratory tract infections are among the most common source of illness in the United States and Europe. Their effects are felt most acutely in susceptible populations, such as children, the elderly, and asthmatic patients. Focusing on the role of Toll-like receptors (TLRs) and nucleotide-binding oligomerization domain (NOD)-like receptors (NLRs), this review will summarize current evidence on how air pollutants might alter innate immunity.

\section{POLLUTANTS AND HEALTH RISKS FROM RESPIRATORY TRACT INFECTIONS}

The strongest evidence of a link between pollutants and respiratory tract infections comes from studies in the developing world of those exposed to the high levels of particles generated from the combustion of biomass fuels (eg, wood and dung) for cooking or heating. Chronic bronchitis, acute respiratory tract infections, recurrent pneumonia, and tuberculosis have all been shown to be significantly more prevalent in mothers who cook or their children. ${ }^{6}$ Fewer studies have been completed in the developed world, where better ventilation results in much lower exposure levels. These studies tend to show an increased risk of acute respiratory tract infections from woodstoves. ${ }^{7}$ Similarly, exposure to CS has long been thought to reduce host defense because smokers have much higher rates of respiratory tract infections. ${ }^{8}$ Numerous studies have now shown that secondhand smoke can also significantly increase the risk from lower respiratory tract infections in children and infants.., 10

The United States Environmental Protection Agency is mandated to set National Ambient Air Quality Standards for 6 criteria pollutants, including ozone and PM. These have tended to receive the most attention of the studies on air pollution and respiratory health effects. Evidence of increased susceptibility to infections from ambient pollutants has come from experimental pulmonary infections. For example, in mice infected with bacteria, exposure to low levels of ozone will increase mortality. ${ }^{11}$ Population-based studies have supported these findings but have not been conclusive because of methodological problems. For example, multiple epidemiologic studies have now shown an association between increases in ambient ozone or PM levels and hospital admissions for respiratory disease. ${ }^{12-16}$ Unfortunately, the difficulty in ascertaining the role of pulmonary infections in these studies limits our ability to determine whether this was due to the pollutants acting on susceptible airways, as in patients with asthma or chronic obstructive pulmonary disease (COPD), or rather an impaired immune response to an infection after pollutant exposure. Hospital visits for PM- 
induced asthma are more prevalent in children and the elderly, ${ }^{15,16}$ yet in these subpopulations viral infection is a primary driver of exacerbations. Complicating the issue is that agents like ozone can cause inflammation and alter the immune system while also having an independent effect on lung function. ${ }^{17}$

As we detail below, pollutants from biomass, CS, and ambient air can work through common mechanisms to alter innate immune responses. Understanding these cellular pathways provides valuable information to address future concerns. Recently, the emerging field of nanotechnology and the resultant explosion in exposure to inhaled engineered nanoparticles has led some to question the potential health risks. Although no populationbased study to date has investigated the association between nanoparticle exposure and respiratory tract infections, given the cellular studies reviewed below, these might be warranted.

\section{PATTERN RECOGNITION RECEPTORS AND RESPONSE TO ENVIRONMENTAL AIR POLLUTION}

Recent studies seeking to determine the receptors and intracellular signaling mechanisms used by airway cells to recognize pollutants and induce an inflammatory response have implicated pattern recognition receptors (PRRs). ${ }^{18}$ These receptors were originally identified as innate immune sensors that function to distinguish innocuous from pathogenic exposures and induce an appropriate inflammatory response. PRRs recognize conserved microbial ligands, termed pathogen-associated molecular patterns (PAMPs), and endogenous ligands derived from stressed cells, termed damage-associated molecular patterns (DAMPs). ${ }^{19}$ Activation of PRRs results in the release of cytokines and chemokines to attract leukocytes and antigen-presenting cells to the site of infection or injury and trigger their maturation. ${ }^{20}$

There are several classes of PRRs, including the TLRs, C-type lectin receptors, retinoic acid-inducible gene I-like receptors, and NLRs. ${ }^{21,22}$ An increasing number of studies have demonstrated the role of TLR signaling in pollutant-induced inflammation. More recently, NLRs and the subset that assemble and oligomerize to form the complex known as the inflammasome have been implicated as an innate immune mechanism that might be involved in the inflammatory response to ambient pollutants. ${ }^{23}$

TLRs

The TLR family is responsible for sensing PAMPs and DAMPs and disseminating the signal to intracellular transcription factors, which regulate cytokine and chemokine gene expression. There are currently 13 identified mammalian TLRs (10 in humans and 12 in mice), which are classified as type 1 transmembrane receptors containing an $\mathrm{N}$-terminal leucine-rich repeat domain, a transmembrane region, and a C-terminal cytoplasmic domain. ${ }^{24}$ TLRs are expressed by a wide variety of hematopoietic cells (eg, macrophages and dendritic cells [DCs]), as well as epithelial cells. ${ }^{25}$ Each TLR is associated with specific recognition patterns: extracellular TLR1, TLR2, TLR4, and TLR5 sense bacterial components, such as lipoproteins and the bacterial wall component LPS (also known as endotoxin), whereas endosomal TLR3, TLR7, TLR8, and TLR9 recognize nucleic acids. ${ }^{22}$ 
Interaction of the TLR with its specific ligand results in the activation of a signaling cascade, leading to the production of innate effector molecules and the initiation of the adaptive immune response (Fig 1). ${ }^{26,27}$ TLRs signal to the cytoplasm through adaptor proteins, such as myeloid differentiation primary response gene 88 (MyD88), TIR domaincontaining adaptor protein, TIR domain-containing adapter-inducing IFN- $\beta$ (TRIF), and translocation-associated membrane protein, all of which harbor a TIR domain for the recruitment of the adaptor protein to the TLR cytoplasmic domain through a TIR-TIR interaction. ${ }^{24}$ MyD88 is an adaptor protein shared by all TLRs except TLR3, which instead uses TRIF to signal to the cytoplasm. The TLR signaling cascades result in the activation of transcription factors in the cytoplasm, such as nuclear factor $\kappa$ light chain enhancer of activated B cells (NF- $\kappa \mathrm{B}$ ), interferon-regulatory factors (IRFs), and mitogen-activated protein kinases, which then induce or inhibit the transcription of genes involved in inflammatory and immune responses. ${ }^{20,28}$ More detailed reviews of TLR signaling have been previously published. ${ }^{28-30}$

Dysfunction of the innate immune system and TLR signaling has been associated with the pathogenesis of several airway diseases, including acute lung injury, asthma, and COPD. ${ }^{20}$ For example, acute lung injury can be triggered by bacterial or viral infections and noninfectious insults, such as environmental exposures (ozone or metals) or trauma, which can stimulate TLR signaling and initiate an inflammatory response and tissue damage. ${ }^{20,31,32}$ Additionally, TLR4, the endotoxin receptor, has been shown to play a role in the induction of the $\mathrm{T}_{\mathrm{H}}$ 2-biased immune response in the lung and the development of asthma. ${ }^{23}$ Consequently, mutations in several TLRs, including TLR4, have been associated with asthma. ${ }^{20,33,34}$ Clearly, the TLR signaling pathways play an important role in initiating the immune response to PAMPs and DAMPs, which, when left unchecked, can lead to tissue injury and airway disease.

Neutrophilic influx is a shared characteristic of exposure to endotoxin and many airway pollutants, including PM, CS, and ozone, suggesting that the inflammatory response might be mediated by a common innate immune mechanism. ${ }^{35}$ Knowledge that TLR4 mediates the inflammatory response to endotoxin has led to the hypothesis that TLR4 might also be involved in the inflammatory response to air pollutants. ${ }^{23}$ More recently, TLRs involved in nucleic acid recognition and antiviral response (TLR3, TLR7, and TLR9) were also shown to be modified by PM or CS. ${ }^{36-38}$ Although numerous studies suggest that air pollutants might alter the activation of TLR signaling, expression of TLR molecules at the membrane, or response to ligands, it is unclear which components of the pollutants are responsible for these changes. TLR activation might also be mediated by a secondary messenger or DAMP produced in response to airway damage, such as heat shock protein 70 (Hsp70) or hyaluronic acid $(\boldsymbol{H A}) .{ }^{20}$ Here we will compare and contrast what is currently known regarding the effects of PM, CS, and ozone on TLR signaling.

\section{PM}

PM-associated biological components (ie, endotoxin, pollen, bacteria, fungal spores, and viruses), soluble metals, and organic content are hypothesized to stimulate a proinflammatory response in the airway that might be mediated by TLR activation. ${ }^{18,39-43}$ 
There are several published studies that investigate the mechanism of PM recognition by TLRs. Becker et al ${ }^{40}$ demonstrated the involvement of TLR2 and TLR4 in the inflammatory response to $\mathrm{PM}_{2.5-10}$ using Chinese hamster ovary cells transfected with CD14 and TLR2 or TLR4. Alveolar macrophages were then treated with a TLR4 antagonist (E5531), which inhibited the $\mathrm{PM}_{2.5-10}$-induced inflammatory response. In contrast to alveolar macrophages, exposure of primary human airway epithelial cells to various sizes of PM resulted in TLR2dependent, TLR4-independent production of IL-8. This response was associated with low expression of TLR4 by the epithelial cells. Interestingly, levels of the DAMP Hsp70 were also increased by PM treatment, suggesting indirect activation of the TLR pathway. ${ }^{44}$ Recently, Shoenfelt et al ${ }^{18}$ suggested that ambient air particles might use distinct receptors and proinflammatory signaling pathways based on particle composition. Exposure of murine peritoneal macrophages to $\mathrm{PM}_{2.5}$, which had high levels of redox active metals and low levels of endotoxin, induced cytokine secretion in a TLR2-dependent mechanism. By comparison, exposure to $\mathrm{PM}_{10}$, which had high levels of endotoxin, induced cytokine secretion in a TLR4-dependent mechanism. Both inflammatory responses were dependent on MyD88 expression, which is consistent with the shared use of MyD88 by TLR2 and TLR4. These studies demonstrate the ability of certain TLRs to recognize PM or PMinduced danger signals and induce an inflammatory response.

In addition to acting as a TLR ligand, PM might modify the ability of TLRs to respond to other ligands and change the nature of the inflammatory response. In a coculture of human monocytes and airway epithelial cells, treatment with diesel exhaust particles (DEPs) enhanced the inflammatory response to low levels of the TLR agonists LPS and flagellin, suggesting that low-level exposure to a pollutant can enhance the proinflammatory potential of future stimuli. ${ }^{45}$ Modifications in the TLR response to an agonist might be the result of altered receptor expression. For example, respiratory epithelial cells exposed to a suspension of aqueous DEPs had increased expression and activity of TLR3, as evidenced by increased $I \boldsymbol{L}-\mathbf{6}$ and IFN- $\beta$ expression in response to the agonist polyinosinic:polycytidylic acid. ${ }^{36} \mathrm{In}$ another study, human airway epithelial cells exposed to PM had increased TLR4 expression and IL-8 production, whereas TLR 2 expression remained constant. ${ }^{44}$ In contrast to the airway epithelial cell response to PM, Williams et $\mathrm{al}^{46}$ demonstrated downregulation of TLR2 and TLR4 expression in human myeloid DCs exposed to PM, which correlated with a pro- $\mathrm{T}_{\mathrm{H}} 2$ inflammatory profile (decreased IL-12 and IL- 6 secretion and increased IL-18 and IL-10 secretion). Thus in addition to acting as a TLR ligand, PM can also prime the airway for a more severe or proallergic response to a subsequent challenge by influencing TLR expression and response.

Similar to PM, CS exposure induces a proinflammatory response while concurrently altering TLR expression and the ability to respond appropriately to PAMPs. Several studies have shown that acute exposure to CS activates TLR4 signaling, leading to neutrophilic inflammation of the airway. Doz et $\mathrm{al}^{47}$ found that acute exposure of $\mathrm{Tlr}^{4^{--}}, \mathrm{Il}-1 \mathrm{rl}^{-{ }^{-}}$, or

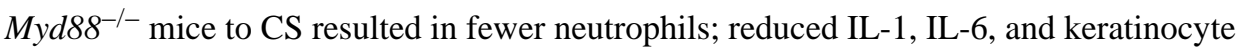
chemoattractant levels; and lower matrix metal-lopeptidase 9 activity in the bronchoalveolar lavage (BAL) fluid compared with those seen in wild-type mice, suggesting that the airway 
inflammation was dependent on TLR4/MyD88 and IL-1 receptor 1/MyD88 signaling. The inflammation was not mediated by endotoxin contamination because CS inhalation did not induce bronchoconstriction, a phenotype of endotoxin exposure. Moreover, the inflammatory effect of CS condensate on in vitro-cultured, bone marrow-derived macrophages was not affected by the addition of polymyxin, an endotoxin inhibitor. Interestingly, CS exposure also heightened levels of the known TLR4 agonist Hsp70 in BAL fluid, suggesting that inflammation might be mediated by a DAMP rather than direct stimulation of TLR4. ${ }^{47}$ Therefore CS might activate TLR4 independently of endotoxin exposure through either direct stimulation or a danger signal.

In vitro exposure to cigarette smoke extract (CSE) also induced the production of TLRmediated proinflammatory cytokines in airway macrophages, plasmacytoid dendritic cells (pDCs), and airway epithelial cells. ${ }^{48-50}$ Pace et al ${ }^{49}$ documented that airway epithelial cells exposed to CSE caused increased expression of TLR4 and heightened production of IL-8, a neutrophil chemoattractant. ${ }^{48}$ Likewise, Mortaz et al ${ }^{48}$ demonstrated that the production of IL-8 was increased by CSE treatment in pDCs. In both of these studies, combined exposure of CSE and TLR agonist further increased IL-8 production while decreasing production of other cytokines and chemokines, including TNF-a, IL-6, interferon a (IFN-a), and IFN- $\gamma-$ induced protein $10(I P-10)$. These studies suggest that CS might activate TLR4, resulting in the induction of some proinflammatory mediators while decreasing the production of other cytokines.

Despite the high level of inflammation in the airway, smokers are known to have poor antiviral defense, which is hypothesized to be in part due to altered TLR stimulation and cytokine production. As mentioned above, CSE exposure decreased production of important innate immune cytokines, including the leukocyte chemoattractant IP-10 in airway epithelial cells and the immune cell activator IFN-a in pDCs. ${ }^{48,49} \mathrm{CSE}$ was also found to inhibit respiratory syncytial virus-induced IFN- $\alpha$, IL- $1 \beta$, IL-10, and IP-10 in pDCs while not affecting the production of other cytokines and chemokines, including IL-6 and TNF- $a$. The reduction of IFN-a production correlated with decreased expression of TLR7 and phosphorylation of downstream IRF7. ${ }^{37}$ Thus CS might potentiate viral symptoms by increasing the proinflammatory environment of the lung while compromising the ability of TLRs to recognize and respond to other stimuli, such as viral infections.

\section{Ozone}

The oxidant gas ozone has also been shown to alter innate immune response and host defense through a TLR4-dependent mechanism. ${ }^{23,51}$ The involvement of TLR4 in ozoneinduced airway injury was first reported by Kleeberger et al, ${ }^{52}$ who examined the response of $\mathrm{C} 3 \mathrm{H} / \mathrm{HeJ}, \mathrm{Tlr}^{-/-}$(HeJ) mice to ozone. Compared with wild-type $\mathrm{C} 3 \mathrm{H} / \mathrm{HeOuJ}$ mice, the HeJ mice had decreased airway permeability and TNF-a expression. Further characterization of the murine model indicated that $\mathrm{Tlr}^{-{ }^{--}}$HeJ mice exposed to ozone had reduced expression of inducible nitric oxide synthase, an enzyme important for the production of nitric oxide (NO) ${ }^{53}$ Because NO plays a role in endotoxin-induced acute lung injury and alveolar epithelial permeability, ${ }^{54}$ this finding suggests that TLR4 modulation of NO synthesis might be one mechanism by which ozone induces airway injury. Subsequent 
study of genetically modified $T l r 4^{-/-}$mice (C57BL/6, $T l r 4^{-/-}$) exposed to ozone indicated that ozone-induced airway hyperresponsiveness was dependent on intact TLR4 signaling. Interestingly, the $T l r 4^{-/-}$and wild-type mice had a similar inflammatory response to ozone, as indicated by comparable neutrophil, cytokine, and protein content in the BAL fluid. ${ }^{55}$ These results suggest that the activation and modulation of TLR4 signaling is an important process in the development of ozone-induced airway injury.

Beyond the mechanistic murine models, TLR4 has been suggested to play a role in the asthmatic human response to ozone. Similar to other air pollutants, ozone has been shown to heighten airway inflammation and modulate the response to subsequent inhaled allergen, particularly in asthmatic subjects who have underlying airway inflammation. ${ }^{5,56} \mathrm{~A}$ recent human study of atopic asthmatic, nonatopic asthmatic, and healthy subjects exposed to 0.4 ppm ozone revealed that the expression of TLR4 by airway macrophages isolated from induced sputum was increased in atopic asthmatic subjects. ${ }^{35}$ This finding was correlated with increased sputum neutrophil numbers and IL-8, IL-6, and IL-1 $\beta$ production. Because asthma is a risk factor for acute ozone-associated respiratory disease, this study suggests that TLR4 might be a pathway through which ozone causes an inflammatory response in allergic asthmatic subjects.

Although these studies indicate a role for TLR4 in response to ozone, specifically how ozone activates TLR4 remains unclear. It is doubtful that ozone, an oxidant gas, is directly recognized by a discrete receptor. Several groups have suggested that ozone-induced airway injury results in the release of DAMPs, which can activate TLR signaling and cause an inflammatory response. Garantziotis et $\mathrm{al}^{57}$ hypothesized that HA can facilitate the inflammatory response to ozone. Mice challenged with ozone had increased HA levels in the BAL fluid. In line with this finding, mice deficient in the primary HA receptor, CD44, had decreased airway hyperresponsiveness and inflammation in response to ozone. Further studies by this group indicated that $T l \mathrm{r}^{-/-}$mice $\left(\mathrm{C} 57 \mathrm{BL} / 6, \mathrm{Tlr}^{-{ }^{-}}\right.$) were protected from airway hyperresponsiveness after ozone exposure and intratracheal instillation of lowmolecular-weight HA. In vitro exposure of bone marrow-derived macrophages to HA resulted in the induction of NF- $\kappa \mathrm{B}$ and the production of proinflammatory cytokines in a pattern characteristic of TLR4 activation. ${ }^{58}$ In addition to HA, levels of Hsp70, a known TLR4 ligand, have been shown to be upregulated in $\mathrm{C} 3 \mathrm{H} / \mathrm{HeOuJ}$ mice after ozone exposure. ${ }^{59}$ Mice deficient in $H s p 70$ (Hspala/hspalbtm1Dix $\left[H s p 70^{-/}\right]$) had reduced ozone-induced inflammation and MyD88 upregulation compared with wild-type $\left(H s p 70^{+/+}\right)$ mice. Together, these studies suggest that ozone-induced inflammation and TLR4 activation are mediated by a secondary messenger or DAMP.

\section{TLR summary}

In summary, this discussion on the effect of air pollutant exposure on TLR signaling highlights several common themes (Fig 2). It is not clear which component of the air pollutants induce a TLR response or whether the effect is mediated by a secondary messenger, such as a DAMP. In the context of PM, endotoxin contamination is likely one constituent that induces TLR signaling. However, for pollutants such as ozone, it is much more likely that a DAMP mediates the TLR response. Regardless of the mechanism, it is 
apparent that air pollutants activate TLR signaling, resulting in a proinflammatory response in the lung. In the process, air pollutants can prime the airway for a modified immune response to subsequent stimuli (eg, by shifting the leukocyte $T_{H} 1 / T_{H} 2$ profile or reducing the production of antiviral cytokines). This effect might be due to alterations in TLR expression. Alternatively, air pollutants might overload the ability of TLRs to respond to ligands. Pollutant-induced alterations in TLR recognition of pathogens might contribute to the increased susceptibility and severity of viral infections and pollutant-induced pathogenesis of airway diseases such as asthma. Further research is necessary to clarify these mechanisms and reveal the implications of pollutant exposure on human disease.

\section{THE INFLAMMASOME AND NLRS}

In addition to the membrane-associated TLRs, PAMPs and DAMPs are also recognized by the cytosolic NLR family of PRRs. NLRs include proteins such as nucleotide-binding oligomerization domain 1 and 2, NOD-like receptor protein 3 (NLRP3, or cryopyrin), and NLR family CARD domain-containing protein 4 (or IPAF). Engagement of these receptors results in a cascade of intracellular signaling, leading to the initiation of an innate immune response. ${ }^{60-62}$ On recognition of a PAMP or DAMP, certain NLRs can form a multiprotein complex termed the inflammasome. The inflammasome is composed of a PRR (NLR or the IFI200 family member absent in melanoma 2), procaspase-1, and the adaptor protein apoptosis speck-like protein containing a CARD (also known as PYCARD). ${ }^{61}$ This complex has been most studied in myeloid cells, particularly macrophages, although recently there has been increased interest in inflammasome signaling in nonmyeloid cells. ${ }^{63}$

On formation of the inflammasome complex, caspase- 1 is autoactivated from the proform to the cleaved active form, which can then catalyze the proteolytic processing and release of IL-1 $\beta$, IL-18, and $I L-33$ (Fig 3). Active caspase-1 might also participate in one of several other effector mechanisms, including induction of a caspase-1-dependent form of programmed cell death termed pyroptosis. ${ }^{64,65}$ Caspase-1-mediated processing and the release of mature cytokines require 2 distinct stimuli. First, an inflammatory stimulus activates the transcription of procytokines, such as pro-IL-1 $\beta$ and pro-IL-18. This signal can be triggered by TLR activation and downstream signaling through the NF- $\kappa \mathrm{B}$ or mitogenactivated protein kinase pathways. The second signal induces activation of the inflammasome, cleavage of caspase-1, and hence procytokine maturation and release.

The exact mechanism of inflammasome activation is not clear. For the prototypical NLRP3 inflammasome, there are 3 proposed models of activation, all of which include cytoplasmic potassium $\left(\mathrm{K}^{+}\right)$efflux from the cell as an important step for inflammasome activation (Fig 3). ${ }^{66-68}$ The channel model of inflammasome activation suggests that ATP-mediated activation of the membrane-associated purinergic receptor $\mathrm{P} 2 \mathrm{X}$ purinoceptor 7 triggers membrane permeability, $\mathrm{K}^{+}$efflux, and pannexin- 1 channel recruitment, thereby allowing direct interaction of the agonist with the NLR. ${ }^{60,66,69}$ Endogenous ATP is a known NLRP3 agonist that is released by injured or necrotic cells. ATP is not required for activation of the inflammasome by some bacterial pathogens, and thus this model might not apply to all NLRP3 agonists. ${ }^{60}$ An alternate hypothesis is the lysosome rupture model, which suggests that the uptake of large particulate activators (eg, alum, asbestos, and silica) leads to 
phagosomal destabilization, lysosomal rupture, and release of the lysosomal protein cathepsin $\mathrm{B}$, which directly or indirectly triggers inflammasome activation. ${ }^{70}$ Finally, the third model proposes that NLRP3 acts as a broad sensor of cellular injury through recognition of oxidative stress, which commonly occurs with $\mathrm{K}^{+}$efflux. ${ }^{70,71}$ Reactive oxygen species (ROS) are generated within and outside of the cell by many NLRP3 agonists, including ATP and the particulate activators asbestos and silica, and thus might play a crucial role in inflammasome activation. Because of the wide range of stimuli recognized by NLRP3, inflammasome activation likely involves a combination of these mechanisms and is tailored for specific stimuli.

Through the recognition of pollutants or pollutant-induced danger signals, the inflammasome might be a pathway by which environmental air pollutants stimulate an innate immune response. Alterations in inflammasome signaling are associated with inflammatory diseases, including gout, autoimmunity, atherosclerosis, Crohn disease, ulcerative colitis, and metabolic disorders. ${ }^{72}$ Moreover, it has recently been shown that lung transplant tissue from chronic smokers and patients with COPD has been shown to have enhanced caspase- 1 activity compared with that seen in nonsmokers. ${ }^{73}$ Thus it is likely that modified inflammasome signaling, as caused by a pollutant exposure or an underlying inflammatory disease, might lead to altered inflammatory responses to pathogens and particles and enhanced pathogenesis in the airway.

The first indication of inflammasome involvement in pollutant-induced inflammation was the finding that the NLRP3 inflammasome was activated by aluminum salts, silica crystals, and asbestos particles in primary murine and human macrophages and the human THP-1 (monocyte) cell line. ${ }^{70,74}$ In both of these studies, the activation of NLRP3 was attributed to phagosomal destabilization. However, Hornung et $\mathrm{al}^{74}$ hypothesized that NLRP3 activation was mediated by lysosomal damage and the release of the lysosomal protein cathepsin B, whereas Dostert et $\mathrm{al}^{70}$ suggested that $\mathrm{K}^{+}$efflux and the generation of ROS was responsible for inflammasome activation. On the basis of these initial findings, the inflammasome has since been shown to be activated by $\mathrm{CS}^{47}$ and nanoparticles ${ }^{75,76}$ but, as yet, not by DEPs. ${ }^{45,70}$

\section{Nanoparticles}

Because of their unique size and physiochemical properties, nanoparticles are becoming increasingly useful for numerous medical (eg, drug delivery), consumer, and industrial applications. However, these same properties raise safety concerns for potential adverse effects on the respiratory system, which serves as both a portal of entry for inhaled particles and a receiver of cardiac output. ${ }^{77}$ Although the toxicity of nanoparticles remains unclear, an increasing number of studies highlight the potential respiratory toxicity of nanoparticles, including several recent studies that indicate that nanoparticles might induce pulmonary inflammation and respiratory disease through a mechanism involving activation of the inflammasome. ${ }^{75,76,78}$ Using genetically engineered mice, Yazdi et al ${ }^{75}$ reported that the IL-1 receptor was necessary for induction of lung inflammation by titanium dioxide $\left(\mathrm{TiO}_{2}\right)$ nanoparticles, suggesting an important role for inflammasome signaling. Using in vitro cultures, $\mathrm{TiO}_{2}$ and silicon dioxide nanoparticle exposure was shown to activate the NLRP3 
inflammasome and IL-1 $\beta$ release in LPS-primed murine bone marrow-derived macrophages and human THP-1 cells. Interestingly, phagocytosis was not required for inflammasome activation by the nanoparticles because silicon dioxide nanoparticles also activated IL-1 $\beta$ secretion in nonphagocytic keratinocytes. Thus nanoparticle exposure might activate the inflammasome through a yet to be determined mechanism, resulting in lung inflammation.

In addition to inflammasome regulation of IL-1 $1 \beta$ release, certain nanoparticles have also been shown to induce an inflammasome-dependent form of cell death termed pyroptosis. Carbon-based nanoparticles are a major constituent of diesel exhaust and ambient PM and are known to cause oxidative stress, inflammation, and cytoxicity. ${ }^{79}$ In a recent study, Reisetter et al ${ }^{76}$ demonstrated that exposure of unprimed macrophages (both the RAW264.7 cell line and primary human alveolar macrophages) to carbon-based nanoparticles, but not $\mathrm{TiO}_{2}$, induced caspase-1-dependent pyroptosis, as evidenced by the loss of plasma membrane integrity, lactate dehydrogenase release, and cellular swelling. Interestingly, carbon-based nanoparticle exposure alone did not induce IL- $1 \beta$ release from macrophages. It was only after LPS priming that the nanoparticles activated caspase- 1 to its cleaved form and increased IL-1 $\beta$ release. These findings suggest that the involvement of caspase- 1 in activities other than IL-1 $\beta$ secretion, such as pyroptosis, might require a different mode of activation independent of TLR activation and cytokine processing. Thus although many studies focus on IL-1 $\beta$ secretion as a marker of inflammasome activation, activity can also be measured through other end points, such as membrane permeability and lactate dehydrogenase release.

\section{CS}

Although nanoparticles act as inflammasome activators, other pollutants might instead be involved in the initiation of procytokine transcription through activation of TLR signaling. A recent study of CS exposure by Doz et $\mathrm{al}^{47}$ highlighted the important association between TLR signaling and inflammasome activation. CS was shown to induce inflammation and increase IL- $1 \beta$ production in the lungs of wild-type mice. However, in mice deficient in IL-1 receptor type $1\left(\mathrm{Il}-1 \mathrm{rr}^{-/}\right)$, exposure to CS resulted in significantly decreased airway inflammation, suggesting that IL-1 signaling was an important mediator of this process. Cultured murine bone marrow-derived macrophages were exposed to cigarette smoke condensate (CSC) and then stimulated with either CSC or ATP to further investigate this finding. CSC exposure alone induced the production of pro-IL-1 $\beta$ but not the release of mature IL-1 $\beta$, whereas the addition of ATP resulted in both the production of pro-IL-1 $\beta$ and the release of mature IL- $1 \beta$. The release of IL- $1 \beta$ was abrogated in $T l r 4^{-/-}$mice. Thus CSC activation of TLR signaling induced production of pro-IL-1 $\beta$, but a second signal, such as ATP, was needed to activate the inflammasome complex. These results suggest that by modulating the activation of TLRs and hence procytokine production, pollutants can prime the cell for an inflammasome-mediated inflammatory response to a second stimulus.

\section{Diesel exhaust}

Beyond acting as stimulators of TLR and NLR signaling, environmental pollutants can indirectly modify inflammasome function by interfering with inflammasome agonists. DEPs are an interesting example of this phenomenon. In an initial study on the effect of 
particulates on inflammasome activation, Dostert et al ${ }^{70}$ reported that exposure of THP-1 cells to DEPs did not result in IL- $1 \beta$ production. A recent study by Chaudhuri et al ${ }^{45}$ elucidated this finding by demonstrating that DEPs had the ability to sequester or breakdown ATP and thereby prevent IL-1 $\beta$ processing and release. By using an epithelial cell/monocyte coculture, it was found that monocyte-derived IL-1 was important for the production of proinflammatory mediators in response to LPS exposure, yet cocultures stimulated with combined LPS and DEPs did not have detectable IL-1 $\beta$. Interestingly, DEP exposure did not alter the production or cleavage of pro-IL-1 $\beta$, and incubation of DEPs with IL-1 $\beta$ did not inhibit recovery or biological action. However, it was found that incubation of ATP with DEPs resulted in a rapid decrease in recoverable ATP. These results suggest that DEPs have the capability to inhibit IL- $1 \beta$ release by interfering with ATP, a molecule known to be involved in IL-1 $\beta$ processing and highlights the possibility that environmental pollutants can alter inflammasome signaling by impeding inflammasome activators.

\section{Inflammasome summary}

It is clear that environmental pollutants can modulate or activate the inflammasome, leading to the production of proinflammatory cytokines. Pollutants are involved in and might interfere with all steps of inflammasome activity, from the initiation of procytokine production to the activation of the NLRs and the release of mature cytokines. Although these processes are only beginning to be understood, pollutants might also induce caspase-1 activities beyond cytokine processing, such as pyroptotic cell death. Although most of these studies investigate pollutant-induced activation of the NLRP3 inflammasome, little is known about the effect of pollutants on other inflammasomes, such as NLRP1, NLR family CARD domain-containing protein 4, or absent in melanoma 2. Although the pollutant might not be specifically recognized by other receptors, pollutants might act as a general stimulant of inflammasome signaling through the initiation of procytokine production. The understanding that procytokine processing requires both TLR and inflammasome activation demonstrates that there is clear cooperation between the TLR and NLR signaling pathways. By acting as a signal for either TLR or NLR signaling, a pollutant might prime the cell for a heightened or modified inflammatory response to a second immune stimulus. In addition, pollutant-induced DAMPs, such as the extracellular matrix proteins $\mathrm{HA}^{79}$ and biglycan, ${ }^{80}$ can activate both TLR and inflammasome activity. Ozone induces the release of ATP by epithelial cells in vitro ${ }^{81}$ and increases levels of HA in animals and human subjects, ${ }^{35,57}$ yet the role of inflammasome-mediated signaling in ozone-induced changes in respiratory immune responses is poorly understood and needs to be further investigated. Future research on the interaction between TLR and NLR signaling might elucidate the adjuvant capabilities of environmental air pollutants and provide another link between pollutant exposure and human airway disease.

\section{CONCLUSION}

Recent discoveries in signaling pathways mediating innate immune responses provide the basis to further our mechanistic understanding of how air pollutants increase susceptibility to pathogens or severity of infection. However, there are several considerations that warrant follow-up studies based on the information provided here. 
First, it is likely that pollutant-induced modifications of innate immune responses and the roles of TLR and NLR pathways are cell type specific. For example, NLRP3 is highly expressed in monocytes/macrophages, conventional DCs, and neutrophils but not in T cells, $\mathrm{B}$ cells, natural killer cells, and eosinophils ${ }^{82}$ or nonmyeloid cells, such as airway epithelial cells. ${ }^{83}$ Studies examining the effects of pollutants on NLR signaling are primarily conducted in models of monocytes/macrophages, which need to be expanded to include other cell types likely to be directly affected by pollutants, such as epithelial cells. Similarly, epithelial cells express TLR1 to TLR6 and TLR9 and respond to activation with microbial ligands specific for TLR2, TLR3, and TLR4. ${ }^{84-86}$ Thus pollutant-induced modulations of TLR and NLR pathways are anticipated to differ among myeloid cells and between immune cells and epithelial cells.

Second, one of the clinically most relevant adverse effects of pollution exposure is exacerbation of pre-existing lung diseases, such as asthma and COPD. Expression, localization, or both of TLRs are modified in epithelial cells from asthmatic subjects ${ }^{87}$ or smokers, ${ }^{49}$ which might affect pollutant-induced effects on TLR signaling. Thus whether and how the disease state alters the effects of air pollutants on TLR and NLR signaling should be considered.

In conclusion, concurrent exposures to pollutants and pathogens are likely, thus making potential interactions between the 2 insults and mechanisms mediating these responses of great public health importance.

\section{GLOSSARY}

CATHEPSIN

\section{CLEAN AIR ACT}

Cathepsins are proteases that are found in lysosomes. Newly discovered functions for cathepsins include activation of the innate immune system. For example, cathepsin $\mathrm{K}$ activates the innate immune system by altering TLR9 signaling and inhibiting the production of IL-6, IL-23, and $\mathrm{T}_{\mathrm{H}} 17$ cells. Phagocytosis of large particles has been shown to cause lysosomal destabilization, leading to the release of cathepsin B from the lysosome and the activation of the NLRP3 inflammasome

The US Clean Air Act was first signed in 1970 and was followed by a number of amendments in 1977 and 1990. The purpose of the Clean Air Act was to protect the public from exposure to high levels of air pollutants. In 1990, the US Environmental Protection Agency estimated that it prevented more than 200,000 premature deaths and almost 700,000 cases of chronic bronchitis in its first 20 years. Since 1970, total emissions of the 6 principal air pollutants have decreased by greater than $41 \%$ 


\section{HYALURONIC ACID \\ (HA)}

IL-6

IL-33

IFN- $\gamma$-INDUCED

PROTEIN 10 (IP-10)

INTERFERONS

\section{MATRIX \\ METALLOPEPTIDASES (MMPs)}

HA is a major component of the extracellular matrix protein that is found in connective, epithelial, and neural tissues. HA is an endogenous DAMP that is recognized by the innate immune system through TLR2 and TLR4, thereby inducing interleukin production (eg, IL-8)

IL-6 acts as both a proinflammatory and antiinflammatory agent but is most commonly associated with acute-phase reactions and fever. IL-6 is released by numerous cell types, including macrophages, dendritic cells, T cells, and epithelial cells. IL-6 can be released in response to various microbial stimuli through activation of pattern recognition receptors (eg, Toll-like receptors)

IL-33 is an IL-1 family member that is produced by epithelial cells, smooth muscle cells, and fibroblasts. IL-33 induces the production of type 2 cytokines, such as IL-5 and IL-13, from $\mathrm{T}_{\mathrm{H}} 2$ cells, mast cells, eosinophils, and basophils. IL-33 is transcribed in a proform, which must be cleaved to the active form by caspase- 1 for secretion

IP-10 (also known as CXCL-10) is secreted by several cell types, such as endothelial cells, epithelial cells, fibroblasts, and monocytes, in response to microbial, IFN$\gamma$, or TNF-a stimulation. IP-10 is involved in chemoattraction of $\mathrm{T}$ and natural killer cells and binds to CXCR3

Interferons are a class of cytokines produced in response to pathogenic infections and tumors. The interferon family consists of type I (IFN- $\alpha$ and IFN- $\beta$ ), type II (IFN- $\gamma$ ), and type III (IFN- $\lambda$ ) interferons. Interferons are produced by activation of Toll-like receptor and retinoic acid-inducible gene I-like receptor signaling. Interferons play a key role in innate immunity through such functions as antiviral defense, activation of immune cells (eg, natural killer cells and macrophages), and upregulation of antigen presentation to $\mathrm{T}$ cells

MMPs, or matrix metalloproteinases, break down extracellular matrix and promote tissue remodeling. MMPs are involved in several physiologic and pathologic processes, including tissue repair, angiogenesis, morphogenesis, cirrhosis, and metastasis. The activity of MMPs is balanced by tissue inhibitors of metalloproteinases (TIMPs). Misbalance between MMPs 


\section{MYELOID \\ DIFFERENTIATION PRIMARY RESPONSE GENE 88 (MYD88)}

\section{NANONOPARTICLES}

OZONE

\section{PARTICULATE MATTER (PM)}

and TIMPs is thought to contribute to asthma pathogenesis

MyD88 is an adaptor protein for all Toll-like receptors except Toll-like receptor 3, as well as IL-1 receptors. MyD88 serves as a link between the extracellular receptors and intracellular signaling pathways leading to activation of the transcription factor NF-kB and expression of many genes important for innate immunity. Autosomal recessive MyD88 deficiency causes increased susceptibility to Streptococcus pneumoniae,

Staphylococcus aureus, and Pseudomonas aeruginosa, as well as other gram-negative infections

Nanoparticles are between 1 and $100 \mathrm{~nm}$ in size and have been used for consumer, manufacturing, and medical purposes (eg, drug delivery). Inhalation of nanoparticles has uncertain pulmonary toxicity but has been increasingly shown to have potential adverse effects on the respiratory tract and vasculature

Ozone is a naturally occurring gas, which can be formed at low levels in the atmosphere through the interaction between hydrocarbons and nitrogen oxides (eg, as produced by fuel exhaust) and sunlight. Because of its strong oxidizing capabilities, ozone is a primary irritant and can affect the eyes and respiratory system. Ozone can induce the production of reactive oxygen species, leading to oxidative stress and tissue and cellular damage

PM consists of solid and liquid compounds from organic, inorganic, and biological sources. A major source of PM is diesel exhaust. $\mathrm{PM}$ is broken into the following 3 classes by size: coarse $\left(\mathrm{PM}_{2.5-10}\right)$, fine $\left(\mathrm{PM}_{0.1-2.5}\right)$, and ultrafine $\left(\mathrm{PM}_{<0.1}\right)$. Fine and ultrafine particles are capable of depositing into the lung, with ultrafine particles reaching the small airways. The components of PM are toxic to cells and can induce DNA damage. Chronic exposure has been associated with airway diseases, such as asthma, and cardiovascular disease

\section{Abbreviations used}

BAL Bronchoalveolar lavage

COPD Chronic obstructive pulmonary disease

CS Cigarette smoke 


\begin{tabular}{ll} 
CSC & Cigarette smoke condensate \\
CSE & Cigarette smoke extract \\
DAMP & Damage-associated molecular pattern \\
DC & Dendritic cell \\
DEP & Diesel exhaust particle \\
HA & Hyaluronic acid \\
Hsp70 & Heat shock protein 70 \\
IP-10 & IFN- $\gamma$-induced protein 10, also known as CXCL10 \\
IRF & Interferon-regulatory factor \\
MyD88 & Myeloid differentiation primary response gene 88 \\
NF- $\boldsymbol{k}$ B & Nuclear factor $\kappa$ light chain enhancer of activated B cells \\
NLR & NOD-like receptor \\
NLRP & NOD-like receptor protein \\
NO & Nitric oxide \\
NOD & Nucleotide-binding oligomerization domain \\
PAMP & Pathogen-associated molecular pattern \\
pDC & Plasmacytoid dendritic cell \\
PM & Particulate matter \\
PRR & Pattern recognition receptor \\
ROS & Reactive oxygen species \\
TiO 2 & Titanium dioxide \\
TIR & Toll-IL-1 receptor \\
TLR & Toll-like receptor \\
TRIF & TIR domain-containing adapter-inducing IFN- $\beta$ \\
\hline
\end{tabular}

\section{References}

1. US Environmental Protection Agency. [Accessed September 7, 2011] Air quality trends. Available at: http://www.epa.gov/airtrends/aqtrends.html. Last updated February 10, 2011

2. American Lung Association. [Accessed September 7, 2011] State of the air. 2011. Available at: http://www.stateoftheair.org/2011/assets/SOTA2011.pdf

3. Bloomberg GR. The influence of environment, as represented by diet and air pollution, upon incidence and prevalence of wheezing illnesses in young children. Curr Opin Allergy Clin Immunol. 2011; 11:144-9. [PubMed: 21368621]

4. Saxon A, Diaz-Sanchez D. Air pollution and allergy: you are what you breathe. Nat Immunol. 2005; 6:223-6. [PubMed: 15716966]

5. Peden D, Reed CE. Environmental and occupational allergies. J Allergy Clin Immunol. 2010; 125(suppl 2):S150-60. [PubMed: 20176257] 
6. Kaplan C. Indoor air pollution from unprocessed solid fuels in developing countries. Rev Environ Health. 2010; 25:221-42. [PubMed: 21038757]

7. Morris K, Morgenlander M, Coulehan JL, Gahagen S, Arena VC. Wood-burning stoves and lower respiratory tract infection in American Indian children. Am J Dis Child. 1990; 144:105-8. [PubMed: 2294707]

8. Huttunen R, Heikkinen T, Syrjanen J. Smoking and the outcome of infection. J Intern Med. 2011; 269:258-69. [PubMed: 21175903]

9. Kum-Nji P, Meloy L, Herrod HG. Environmental tobacco smoke exposure: prevalence and mechanisms of causation of infections in children. Pediatrics. 2006; 117:1745-54. [PubMed: 16651333]

10. Strachan DP, Cook DG. Health effects of passive smoking. 1. parental smoking and lower respiratory illness in infancy and early childhood. Thorax. 1997; 52:905-14. [PubMed: 9404380]

11. Mikerov AN, Gan X, Umstead TM, Miller L, Chinchilli VM, Phelps DS, et al. Sex differences in the impact of ozone on survival and alveolar macrophage function of mice after Klebsiella pneumoniae infection. Respir Res. 2008; 9:24. [PubMed: 18307797]

12. Fusco D, Forastiere F, Michelozzi P, Spadea T, Ostro B, Arca M, et al. Air pollution and hospital admissions for respiratory conditions in Rome, Italy. Eur Respir J. 2001; 17:1143-50. [PubMed: 11491157]

13. Spix C, Anderson HR, Schwartz J, Vigotti MA, LeTertre A, Vonk JM, et al. Short-term effects of air pollution on hospital admissions of respiratory diseases in Europe: a quantitative summary of APHEA study results. Air pollution and health: a European approach. Arch Environ Health. 1998; 53:54-64. [PubMed: 9570309]

14. Atkinson RW, Anderson HR, Sunyer J, Ayres J, Baccini M, Vonk JM, et al. Acute effects of particulate air pollution on respiratory admissions: results from APHEA 2 project. Air pollution and health: a European approach. Am J Respir Crit Care Med. 2001; 164:1860-6. [PubMed: 11734437]

15. Migliaretti G, Cadum E, Migliore E, Cavallo F. Traffic air pollution and hospital admission for asthma: a case-control approach in a Turin (Italy) population. Int Arch Occup Environ Health. 2005; 78:164-9. [PubMed: 15726395]

16. Sun HL, Chou MC, Lue KH. The relationship of air pollution to ED visits for asthma differ between children and adults. Am J Emerg Med. 2006; 24:709-13. [PubMed: 16984840]

17. Kim CS, Alexis NE, Rappold AG, Kehrl H, Hazucha MJ, Lay JC, et al. Lung function and inflammatory responses in healthy young adults exposed to $0.06 \mathrm{ppm}$ ozone for 6.6 hours. Am J Respir Crit Care Med. 2011; 183:1215-21. [PubMed: 21216881]

18. Shoenfelt J, Mitkus RJ, Zeisler R, Spatz RO, Powell J, Fenton MJ, et al. Involvement of TLR2 and TLR4 in inflammatory immune responses induced by fine and coarse ambient air particulate matter. J Leukoc Biol. 2009; 86:303-12. [PubMed: 19406832]

19. Bianchi ME. DAMPs, PAMPs and alarmins: all we need to know about danger. J Leukoc Biol. 2007; 81:1-5. [PubMed: 17032697]

20. Lafferty EI, Qureshi ST, Schnare M. The role of toll-like receptors in acute and chronic lung inflammation. J Inflamm (Lond). 2010; 7:57. [PubMed: 21108806]

21. Peiser L, Mukhopadhyay S, Gordon S. Scavenger receptors in innate immunity. Curr Opin Immunol. 2002; 14:123-8. [PubMed: 11790542]

22. Takeuchi O, Akira S. Pattern recognition receptors and inflammation. Cell. 2010; 140:805-20. [PubMed: 20303872]

23. Peden DB. The role of oxidative stress and innate immunity in $\mathrm{O}(3)$ and endotoxin-induced human allergic airway disease. Immunol Rev. 2011; 242:91-105. [PubMed: 21682740]

24. Watters TM, Kenny EF, O'Neill LA. Structure, function and regulation of the Toll/IL-1 receptor adaptor proteins. Immunol Cell Biol. 2007; 85:411-9. [PubMed: 17667936]

25. West AP, Koblansky AA, Ghosh S. Recognition and signaling by toll-like receptors. Annu Rev Cell Dev Biol. 2006; 22:409-37. [PubMed: 16822173]

26. Iwasaki A, Medzhitov R. Toll-like receptor control of the adaptive immune responses. Nat Immunol. 2004; 5:987-95. [PubMed: 15454922] 
27. Kumar H, Kawai T, Akira S. Pathogen recognition in the innate immune response. Biochem J. 2009; 420:1-16. [PubMed: 19382893]

28. Kawai T, Akira S. Toll-like receptor and RIG-I-like receptor signaling. Ann N Y Acad Sci. 2008; 1143:1-20. [PubMed: 19076341]

29. Lee MS, Kim YJ. Signaling pathways downstream of pattern-recognition receptors and their cross talk. Annu Rev Biochem. 2007; 76:447-80. [PubMed: 17328678]

30. O'Neill LA, Bowie AG. The family of five: TIR-domain-containing adaptors in toll-like receptor signalling. Nat Rev Immunol. 2007; 7:353-64. [PubMed: 17457343]

31. Jiang D, Liang J, Fan J, Yu S, Chen S, Luo Y, et al. Regulation of lung injury and repair by tolllike receptors and hyaluronan. Nat Med. 2005; 11:1173-9. [PubMed: 16244651]

32. Jiang D, Liang J, Li Y, Noble PW. The role of toll-like receptors in non-infectious lung injury. Cell Res. 2006; 16:693-701. [PubMed: 16894359]

33. Fageras Bottcher M, Hmani-Aifa M, Lindstrom A, Jenmalm MC, Mai XM, Nilsson L, et al. A TLR4 polymorphism is associated with asthma and reduced lipopolysaccharide-induced interleukin-12(p70) responses in Swedish children. J Allergy Clin Immunol. 2004; 114:561-7. [PubMed: 15356557]

34. Corr SC, O'Neill LA. Genetic variation in toll-like receptor signalling and the risk of inflammatory and immune diseases. J Innate Immun. 2009; 1:350-7. [PubMed: 20375592]

35. Hernandez ML, Lay JC, Harris B, Esther CR Jr, Brickey WJ, Bromberg PA, et al. Atopic asthmatic subjects but not atopic subjects without asthma have enhanced inflammatory response to ozone. J Allergy Clin Immunol. 2010; 126:537-44. e1. [PubMed: 20816188]

36. Ciencewicki J, Brighton L, Wu WD, Madden M, Jaspers I. Diesel exhaust enhances virus- and poly(I: C)-induced toll-like receptor 3 expression and signaling in respiratory epithelial cells. Am J Physiol Lung Cell Mol Physiol. 2006; 290:L1154-63. [PubMed: 16399790]

37. Castro SM, Chakraborty K, Guerrero-Plata A. Cigarette smoke suppresses TLR-7 stimulation in response to virus infection in plasmacytoid dendritic cells. Toxicol In Vitro. 2011; 25:1106-13. [PubMed: 21435390]

38. Mortaz E, Adcock IM, Ito K, Kraneveld AD, Nijkamp FP, Folkerts G. Cigarette smoke induces CXCL8 production by human neutrophils via activation of TLR9 receptor. Eur Respir J. 2010; 36:1143-54. [PubMed: 19840968]

39. Dye JA, Adler KB, Richards JH, Dreher KL. Role of soluble metals in oil fly ash-induced airway epithelial injury and cytokine gene expression. Am J Physiol Lung Cell Mol Physiol. 1999; 277:L498-510.

40. Becker S, Fenton MJ, Soukup JM. Involvement of microbial components and toll-like receptors 2 and 4 in cytokine responses to air pollution particles. Am J Respir Cell Mol Biol. 2002; 27:611-8. [PubMed: 12397021]

41. Goulaouic S, Foucaud L, Bennasroune A, Laval-Gilly P, Falla J. Effect of polycyclic aromatic hydrocarbons and carbon black particles on pro-inflammatory cytokine secretion: impact of PAH coating onto particles. J Immunotoxicol. 2008; 5:337-45. [PubMed: 18830893]

42. Hopke PK, Rossner A. Exposure to airborne particulate matter in the ambient, indoor, and occupational environments. Clin Occup Environ Med. 2006; 5:747-71. [PubMed: 17110290]

43. Inoue K, Takano H, Yanagisawa R, Hirano S, Ichinose T, Shimada A, et al. The role of toll-like receptor 4 in airway inflammation induced by diesel exhaust particles. Arch Toxicol. 2006; 80:275-9. [PubMed: 16254717]

44. Becker S, Dailey L, Soukup JM, Silbajoris R, Devlin RB. TLR-2 is involved in airway epithelial cell response to air pollution particles. Toxicol Appl Pharmacol. 2005; 203:45-52. [PubMed: 15694463]

45. Chaudhuri N, Paiva C, Donaldson K, Duffin R, Parker LC, Sabroe I. Diesel exhaust particles override natural injury-limiting pathways in the lung. Am J Physiol Lung Cell Mol Physiol. 2010; 299:L263-71. [PubMed: 20435687]

46. Williams MA, Porter M, Horton M, Guo J, Roman J, Williams D, et al. Ambient particulate matter directs nonclassic dendritic cell activation and a mixed TH1/TH2-like cytokine response by naive CD4+ T cells. J Allergy Clin Immunol. 2007; 119:488-97. [PubMed: 17187851] 
47. Doz E, Noulin N, Boichot E, Guenon I, Fick L, Le Bert M, et al. Cigarette smoke-induced pulmonary inflammation is TLR4/MyD88 and IL-1R1/MyD88 signaling dependent. J Immunol. 2008; 180:1169-78. [PubMed: 18178857]

48. Mortaz E, Lazar Z, Koenderman L, Kraneveld AD, Nijkamp FP, Folkerts G. Cigarette smoke attenuates the production of cytokines by human plasmacytoid dendritic cells and enhances the release of IL-8 in response to TLR-9 stimulation. Respir Res. 2009; 10:47. [PubMed: 19515231]

49. Pace E, Ferraro M, Siena L, Melis M, Montalbano AM, Johnson M, et al. Cigarette smoke increases toll-like receptor 4 and modifies lipopolysaccharide-mediated responses in airway epithelial cells. Immunology. 2008; 124:401-11. [PubMed: 18217953]

50. Sarir H, Mortaz E, Karimi K, Kraneveld AD, Rahman I, Caldenhoven E, et al. Cigarette smoke regulates the expression of TLR4 and IL-8 production by human macrophages. J Inflamm (Lond). 2009; 6:12. [PubMed: 19409098]

51. Hollingsworth JW, Kleeberger SR, Foster WM. Ozone and pulmonary innate immunity. Proc Am Thorac Soc. 2007; 4:240-6. [PubMed: 17607006]

52. Kleeberger SR, Reddy S, Zhang LY, Jedlicka AE. Genetic susceptibility to ozone-induced lung hyperpermeability: role of toll-like receptor 4. Am J Respir Cell Mol Biol. 2000; 22:620-7. [PubMed: 10783135]

53. Kleeberger SR, Reddy SP, Zhang LY, Cho HY, Jedlicka AE. Toll-like receptor 4 mediates ozoneinduced murine lung hyperpermeability via inducible nitric oxide synthase. Am J Physiol Lung Cell Mol Physiol. 2001; 280:L326-33. [PubMed: 11159012]

54. Li XY, Donaldson K, MacNee W. Lipopolysaccharide-induced alveolar epithelial permeability: the role of nitric oxide. Am J Respir Crit Care Med. 1998; 157:1027-33. [PubMed: 9563715]

55. Hollingsworth JW 2nd, Cook DN, Brass DM, Walker JK, Morgan DL, Foster WM, et al. The role of toll-like receptor 4 in environmental airway injury in mice. Am J Respir Crit Care Med. 2004; 170:126-32. [PubMed: 15020293]

56. Jorres R, Nowak D, Magnussen H. The effect of ozone exposure on allergen responsiveness in subjects with asthma or rhinitis. Am J Respir Crit Care Med. 1996; 153:56-64. [PubMed: 8542163]

57. Garantziotis S, Li Z, Potts EN, Kimata K, Zhuo L, Morgan DL, et al. Hyaluronan mediates ozoneinduced airway hyperresponsiveness in mice. J Biol Chem. 2009; 284:11309-17. [PubMed: 19164299]

58. Garantziotis S, Li Z, Potts EN, Lindsey JY, Stober VP, Polosukhin VV, et al. TLR4 is necessary for hyaluronan-mediated airway hyperresponsiveness after ozone inhalation. Am J Respir Crit Care Med. 2010; 181:666-75. [PubMed: 20007931]

59. Bauer AK, Rondini EA, Hummel KA, Degraff LM, Walker C, Jedlicka AE, et al. Identification of candidate genes downstream of TLR4 signaling after ozone exposure in mice: a role for heatshock protein 70. Environ Health Perspect. 2011; 119:1091-7. [PubMed: 21543283]

60. Mariathasan S, Monack DM. Inflammasome adaptors and sensors: intracellular regulators of infection and inflammation. Nat Rev Immunol. 2007; 7:31-40. [PubMed: 17186029]

61. Kanneganti TD. Central roles of NLRs and inflammasomes in viral infection. Nat Rev Immunol. 2010; 10:688-98. [PubMed: 20847744]

62. Franchi L, Eigenbrod T, Munoz-Planillo R, Nunez G. The inflammasome: a caspase-1-activation platform that regulates immune responses and disease pathogenesis. Nat Immunol. 2009; 10:2417. [PubMed: 19221555]

63. Yazdi AS, Drexler SK, Tschopp J. The role of the inflammasome in nonmyeloid cells. J Clin Immunol. 2010; 30:623-7. [PubMed: 20582456]

64. Lamkanfi M. Emerging inflammasome effector mechanisms. Nat Rev Immunol. 2011; 11:213-20. [PubMed: 21350580]

65. Miao EA, Rajan JV, Aderem A. Caspase-1-induced pyroptotic cell death. Immunol Rev. 2011; 243:206-14. [PubMed: 21884178]

66. Tschopp J, Schroder K. NLRP3 inflammasome activation: the convergence of multiple signalling pathways on ROS production? Nat Rev Immunol. 2010; 10:210-5. [PubMed: 20168318]

67. Martinon F, Mayor A, Tschopp J. The inflammasomes: guardians of the body. Annu Rev Immunol. 2009; 27:229-65. [PubMed: 19302040] 
68. Petrilli V, Papin S, Dostert C, Mayor A, Martinon F, Tschopp J. Activation of the NALP3 inflammasome is triggered by low intracellular potassium concentration. Cell Death Differ. 2007; 14:1583-9. [PubMed: 17599094]

69. Di Virgilio F, Baricordi OR, Romagnoli R, Baraldi PG. Leukocyte P2 receptors: A novel target for anti-inflammatory and anti-tumor therapy. Curr Drug Targets Cardiovasc Haematol Disord. 2005; 5:85-99. [PubMed: 15720226]

70. Dostert C, Petrilli V, Van Bruggen R, Steele C, Mossman BT, Tschopp J. Innate immune activation through Nalp3 inflammasome sensing of asbestos and silica. Science. 2008; 320:674-7. [PubMed: 18403674]

71. Zhou R, Tardivel A, Thorens B, Choi I, Tschopp J. Thioredoxin-interacting protein links oxidative stress to inflammasome activation. Nat Immunol. 2010; 11:136-40. [PubMed: 20023662]

72. Davis BK, Wen H, Ting JP. The inflammasome NLRs in immunity, inflammation, and associated diseases. Annu Rev Immunol. 2011; 29:707-35. [PubMed: 21219188]

73. Eltom S, Stevenson CS, Rastrick J, Dale N, Raemdonck K, Wong S, et al. P2X7 receptor and caspase 1 activation are central to airway inflammation observed after exposure to tobacco smoke. PLoS One. 2011; 6:e24097. [PubMed: 21915284]

74. Hornung V, Bauernfeind F, Halle A, Samstad EO, Kono H, Rock KL, et al. Silica crystals and aluminum salts activate the NALP3 inflammasome through phagosomal destabilization. Nat Immunol. 2008; 9:847-56. [PubMed: 18604214]

75. Yazdi AS, Guarda G, Riteau N, Drexler SK, Tardivel A, Couillin I, et al. Nanoparticles activate the NLR pyrin domain containing 3 (Nlrp3) inflammasome and cause pulmonary inflammation through release of IL-1alpha and IL-1beta. Proc Natl Acad Sci U S A. 2010; 107:19449-54. [PubMed: 20974980]

76. Reisetter AC, Stebounova LV, Baltrusaitis J, Powers L, Gupta A, Grassian VH, et al. Induction of inflammasome-dependent pyroptosis by carbon black nanoparticles. J Biol Chem. 2011; 286:21844-52. [PubMed: 21525001]

77. Card JW, Zeldin DC, Bonner JC, Nestmann ER. Pulmonary applications and toxicity of engineered nanoparticles. Am J Physiol Lung Cell Mol Physiol. 2008; 295:L400-11. [PubMed: 18641236]

78. Demento SL, Eisenbarth SC, Foellmer HG, Platt C, Caplan MJ, Mark Saltzman W, et al. Inflammasome-activating nanoparticles as modular systems for optimizing vaccine efficacy. Vaccine. 2009; 27:3013-21. [PubMed: 19428913]

79. Yamawaki H, Iwai N. Mechanisms underlying nanosized air-pollution-mediated progression of atherosclerosis: carbon black causes cytotoxic injury/inflammation and inhibits cell growth in vascular endothelial cells. Circ J. 2006; 70:129-40. [PubMed: 16377937]

80. Babelova A, Moreth K, Tsalastra-Greul W, Zeng-Brouwers J, Eickelberg O, Young MF, et al. Biglycan, a danger signal that activates the NLRP3 inflammasome via toll-like and P2X receptors. J Biol Chem. 2009; 284:24035-48. [PubMed: 19605353]

81. Ahmad S, Ahmad A, McConville G, Schneider BK, Allen CB, Manzer R, et al. Lung epithelial cells release ATP during ozone exposure: signaling for cell survival. Free Radic Biol Med. 2005; 39:213-26. [PubMed: 15964513]

82. Guarda G, Zenger M, Yazdi AS, Schroder K, Ferrero I, Menu P, et al. Differential expression of NLRP3 among hematopoietic cells. J Immunol. 2011; 186:2529-34. [PubMed: 21257968]

83. Allen IC, Scull MA, Moore CB, Holl EK, McElvania-TeKippe E, Taxman DJ, et al. The NLRP3 inflammasome mediates in vivo innate immunity to influenza A virus through recognition of viral RNA. Immunity. 2009; 30:556-65. [PubMed: 19362020]

84. Sha Q, Truong-Tran AQ, Plitt JR, Beck LA, Schleimer RP. Activation of airway epithelial cells by toll-like receptor agonists. Am J Respir Cell Mol Biol. 2004; 31:358-64. [PubMed: 15191912]

85. Armstrong L, Medford AR, Uppington KM, Robertson J, Witherden IR, Tetley TD, et al. Expression of functional toll-like receptor-2 and -4 on alveolar epithelial cells. Am J Respir Cell Mol Biol. 2004; 31:241-5. [PubMed: 15044215]

86. Guillot L, Le Goffic R, Bloch S, Escriou N, Akira S, Chignard M, et al. Involvement of toll-like receptor 3 in the immune response of lung epithelial cells to double-stranded RNA and influenza A virus. J Biol Chem. 2005; 280:5571-80. [PubMed: 15579900] 
87. Cottey L, Jayasekera N, Haitchi H, Green B, Grainge C, Howarth P. S42 airway epithelial toll receptor expression in asthma and its relationship to disease severity. Thorax. 2010; 65:A21-2. 


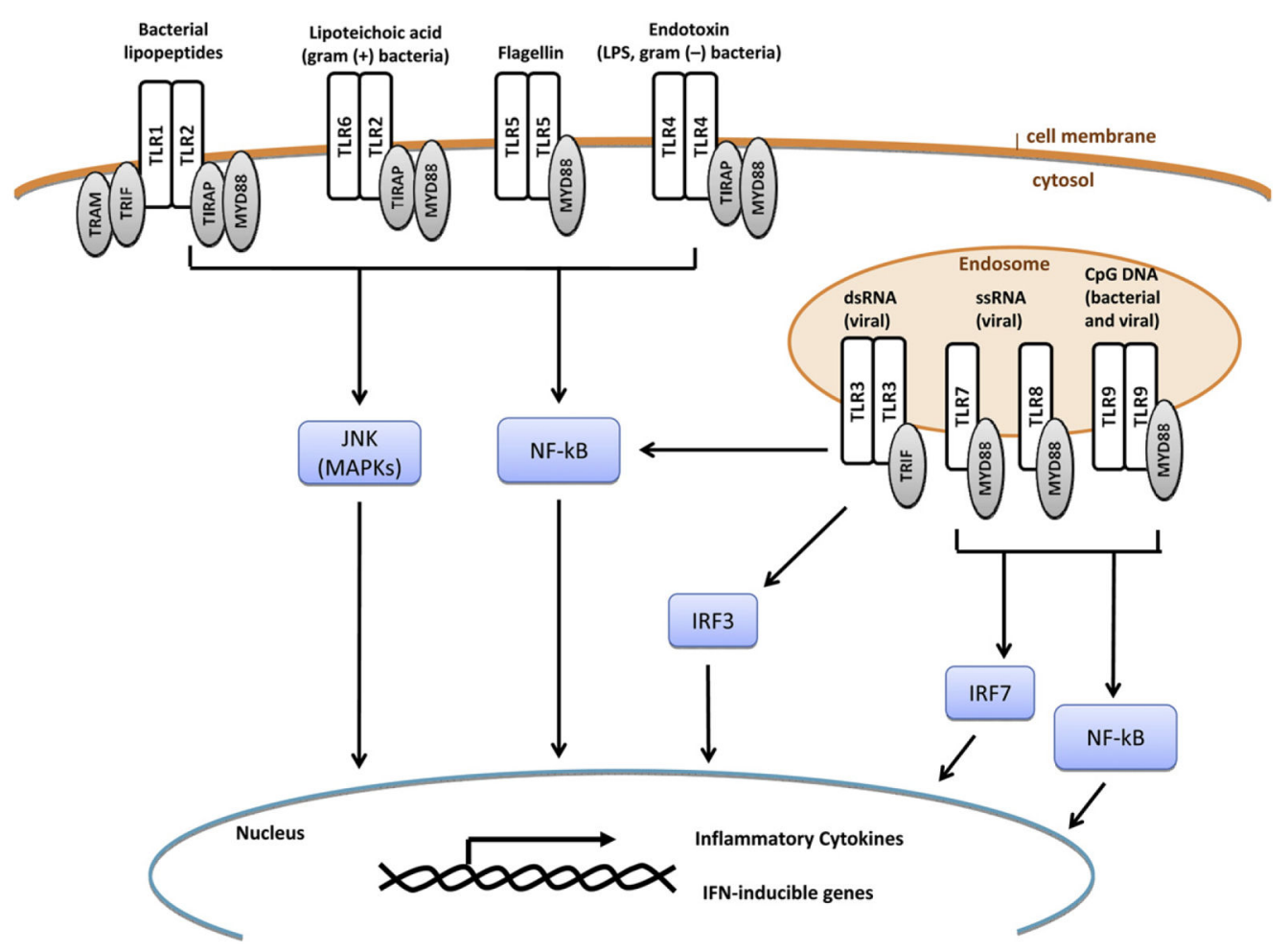

FIG 1.

Summary of TLR signaling. TLRs are transmembrane receptors that might exist either extracellularly at the cellular membrane or intracellularly at the endosomal membrane. Each TLR recognizes specific ligands and signals to cytosolic molecules through adaptor proteins, including translocation-associated membrane protein (TRAM), TRIF, TIR domaincontaining adaptor protein (TIRAP), and MyD88. The end result of TLR signaling is the activation of mitogen-activated protein kinase (MAPK), NF- $\kappa \mathrm{B}$, and IRF3/7, leading to the transcription of proinflammatory cytokines and IFN-inducible genes. $d s R N A$, Doublestranded RNA; JNK, c-Jun N-terminal kinase; ssRNA, single-stranded RNA. 


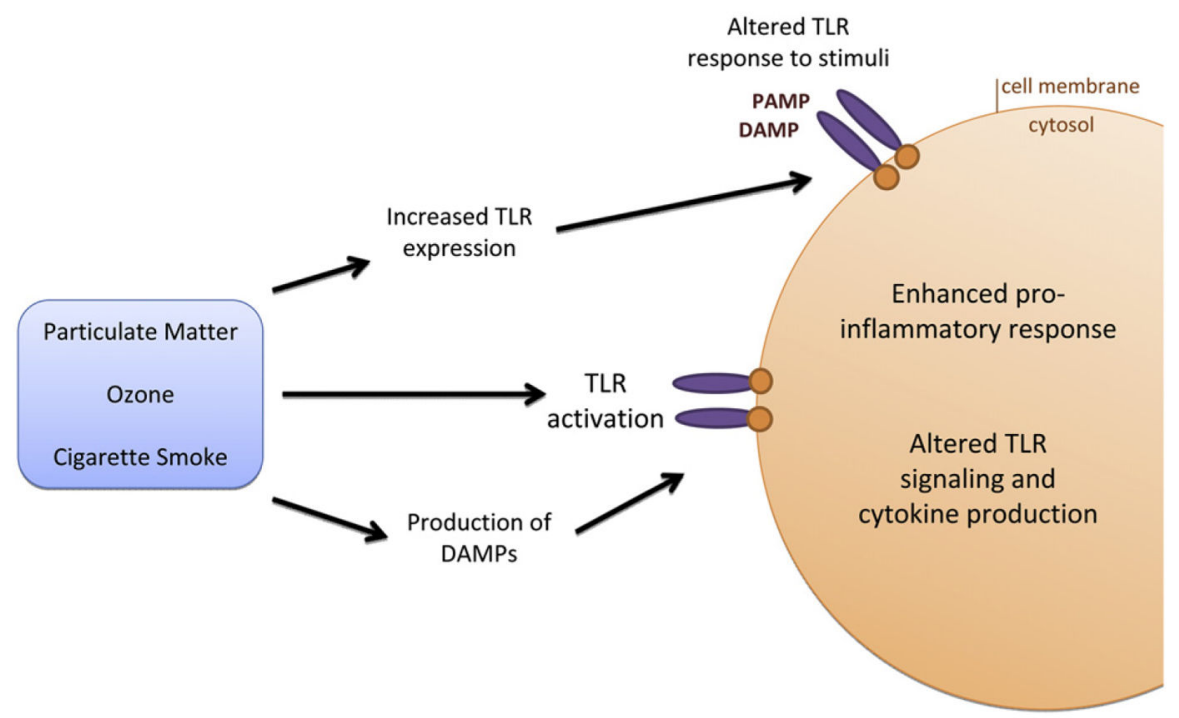

FIG 2.

Exposure to air pollutants modifies TLR-dependent signaling. Air pollutants, such as PM, ozone, and CS, might activate TLR signaling through either direct interaction with the receptor or through the production of a secondary mediator, such as a DAMP. Alternatively, the pollutants might indirectly alter TLR signaling by modifying the response to a PAMP or DAMP. Modifications in TLR signaling result in altered cytokine profiles and an enhanced proinflammatory response in the lung. 


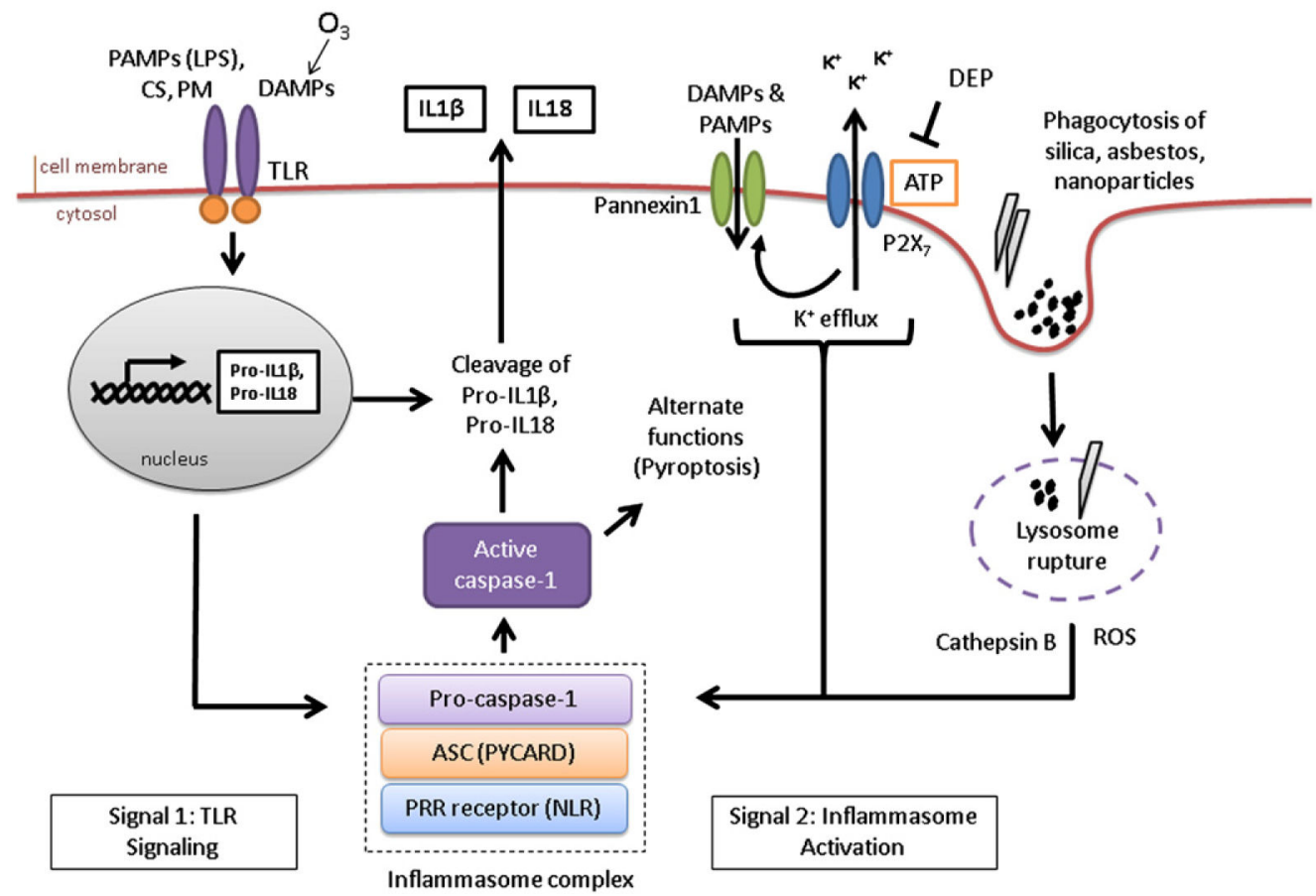

FIG 3.

NLR- and inflammasome-dependent signaling is altered by exposure to air pollutants. Air pollutants are involved in or interfere with all steps of inflammasome activity. CS and PMassociated endotoxin (LPS) initiate the production of pro-IL-1 $\beta$ through activation of TLR signaling. Nanoparticles, silica, and asbestos directly activate NLR signaling and inflammasome formation through a mechanism that might involve phagocytosis, lysosome rupture, potassium $\left(\mathrm{K}^{+}\right)$efflux, and the production of ROS. Nanoparticles might induce additional caspase- 1 activities, including pyroptosis. Pollutant-induced DAMPs, such as HA (induced by ozone exposure), can also act as activators of TLRs and NLRs. Air pollutants can also inhibit inflammasome activities. DEPs were shown to scavenge the inflammasome activator ATP and prevent mature cytokine release. 